\title{
Arbitragem Global: Harmonizada
}

\section{Global Arbitration: Harmonized}

\author{
Eugênio Pacceli de Morais Bomtempo ${ }^{1 *}$
}

\begin{abstract}
RESUMO
Este trabalho examina a relação entre a expansão dos negócios globalizados com a harmonização existente nos procedimentos arbitrais internacionais, processo que se desenvolve em caráter irreversível. Aproximadamente $60 \%$ dos negócios mundiais ocorrem entre as próprias empresas transacionais. A pesquisa adota metodologia qualitativa, com exames dos regulamentos das principais Cortes arbitrais, para testar a hipótese que os valores transacionais são elevados, assim, o sigilo se faz recomendável por questão como velocidade, produtividade, segurança operacional das empresas controvertidas, garantia de liberdade em face dos órgãos de controle dos Estados nacionais e fator de proteção tributária. Foi possível identificar que há estreita conexão de interesses entre a atuação das empresas transnacionais, em prol da expansão de arbitragens imparciais, rápidas, sigilosas, independentes e flexíveis. Há um trade-off entre a necessidade de velocidade na solução de controvérsias e deter a opacidade de transações se algum interesse público for ferido. No entanto, devido à correlação entre os aspectos macroeconômicos dos negócios transnacionais e a expansão das Cortes arbitrais esta percepção traz um plus de ganhos de produtividade.
\end{abstract}

Palavras chaves: Arbitragem; Transnacional; Sigilo; Negócios

\begin{abstract}
This paper examines the relationship between the expansion of globalized businesses and the existing harmonization in international arbitration that develops irreversibly. Approximately $60 \%$ of global business takes place between multinationals Companies. This research adopts qualitative methodology, with exams some rules of arbitration courts, to test the hypothesis that transactional values are high, thus, secrecy is recommended for reasons of speed, productivity, operational security of the companies, guarantee of freedom in the face national state control bodies and tax protection factor. It was possible to identify that there is a close connection of interests between the performance of transnational companies and the expansion of impartial, fast, confidential, independent, and flexible arbitrations. There is a trade-off between the need for speed in resolving disputes and stopping the opacity of transactions if any public interest hurted. However, due to the correlation between the macroeconomic aspects of transnational businesses and the expansion of the Arbitral Courts, this perception brings a plus to the understanding of productivity.
\end{abstract}

Keywords: Arbitration; Transnational; Confidential; Business

\footnotetext{
${ }^{1}$ Centro Universitário de Brasília - UNICEUB

*E-mail: eugenio.bomtempo@gmail.com
} 


\section{INTRODUÇÃO}

Os procedimentos arbitrais são basicamente harmônicos no Mundo. São flexíveis, sigilosos e independentes nas cortes arbitrais internacionais. Há uma verdadeira expansão de atuação da arbitragem internacional se desenvolvendo na mesma proporção da globalização. Examinando-se os procedimentos das cortes arbitrais internacionais surgiu um questionamento: por que são tão semelhantes estes procedimentos das cortes instaladas em locais diferentes do Globo Terrestre?

A harmonização procedimental arbitral é uma tendência irreversível guiada pelo processo de aprofundamento da economia virtual internacional. A maior parte dos negócios mundiais ocorre de forma transfronteiriça, on-line. $\mathrm{O}$ poder do comércio exterior influiu nos costumes das trocas internacionais e nacionais, até se consolidarem nos dias atuais. Assim, este artigo examina a evolução do instituto da arbitragem, a relação existente entre a expansão dos negócios globalizados e a harmonização e flexibilização dos procedimentos arbitrais. A maior parte dos negócios ocorre entre as próprias empresas multinacionais. A economia virtual on-line, de forma eficiente, exige soluções rápidas.

Mas, por qual razão dos procedimentos arbitrais são sigilosos? Esta pesquisa toma como hipótese que os valores transacionais são tão elevados que o sigilo é uma questão de velocidade, produtividade, segurança operacional, garantia de liberdade em face dos órgãos de controle dos Estados nacionais e fator de proteção tributária.

Adotou como metodologia qualitativa nesta pesquisa, tópica, exames bibliográficos, textos normativos literais e a jurisprudência do Superior Tribunal de Justiça, para o teste parcial da hipótese. No primeiro capítulo será feita uma descrição de como funcionam as cortes arbitrais internacionais, para a verificação de seus procedimentos semelhantes e harmônicos. Já no segundo capítulo estuda-se como funciona a arbitragem no Brasil e quais desdobramentos jurisprudenciais se destacam.

Sem esgotar a questão, este pequeno exame ilumina um campo interessantíssimo de pesquisa, de atuação negocial e de formação de árbitros, para atuações empresariais e na esfera do direito internacional privado. Espera-se, que novos estudos sejam despertados.

\section{ARBITRAGEM INTERNACIONAL}


Em 1985 a Comissão das Nações Unidas para a Legislação Comercial Internacional - UNCITRAL elaborou regras de arbitragem, em 41 artigos, para regular os procedimentos arbitrais internacionais, desde o requerimento, notificação até a sentença. $\mathrm{O}$ termo comercial deve ser compreendido no sentido amplo, de forma a abranger qualquer relação de natureza comercial, contratual ou não contratual (MANGE et al., 2020).

A “arbitragem transnacional” volta-se para soluções de impasses comerciais entre empresas ou equiparadas, geralmente, envolvendo negócios de multinacionais, contratos internacionais, ou seja, volta-se a solucionar conflitos de interesses de relações de transações transnacionais, conforme Pinheiro (2003), pois sujeitas a pluralidade de ordenamentos jurídicos dentro do direito internacional privado.

No entanto, a "arbitragem internacional" também pode ser aplicada a soluções calcadas em Direito Internacional Público, ou seja, entre Entes com personalidade jurídica internacional de direito público, envolvendo interesses de nações soberanas. O Direito Transnacional, ou lex mercatoria, enquanto normas jurídicas espontâneas surgidas na Europa e que se notabilizaram no direito internacional privado, tem grande importância nas relações de costumes consagrados, operações e regras convencionais de comércio internacional, na formação das sentenças arbitrais, entre outros.

$\mathrm{Na}$ atual versão da Lex Mercatoria órgãos decisores são criados pelos agentes privados para atuarem diretamente em fatos transnacionais, em processos ágeis e se pautando por regras decentralizadas, em um pluralismo jurídico, o que afeta os mercados nacionais positiva e negativamente, a gerar conflitos, a exigir soluções flexíveis e rápidas sem depender só do direito interno das nações. Assim, "a nova sociedade transnacional precisou, desde o seu início, se alinhar conforme costumes, convenções e por um direito específico" (FONASTER; SOARES, 2020).

Observa-se, que não se pode abordar a arbitragem transnacional sem computar os efeitos da globalização no mundo dos negócios transfronteiriços. Como bem explicam Fonaster e Soares, a globalização não se prende somente a aspectos meramente econômicos, mas consideram três níveis de atuação empresarial: a empresa, o mercado e a regulação envolvida. Dado o avanço tecnológico, processo de globalização mostra-se irreversível e, também, pode influenciar o surgimento de novas regras e paradigmas de direito internacional privado.

Nos Estados Unidos, quando a questão envolve interesse público existe uma norma de conduta: o Administrative Dispute Resolution Act of 1996, que dispõe a ambas as partes 
contratantes a faculdade de consentirem se submeter ao procedimento arbitral. No entanto, a instituição pública tem restrições para esta adesão: se implicar externalidades a terceiros, conforme o valor presente, se ferir alguma política pública do governo (USA, 1996).

$\mathrm{Na}$ esfera internacional, para atender tamanha extensão de negócios em vários locais do Planeta, proliferam-se as cortes arbitrais (CALMON, 2020), por exemplo: CCI Câmara de Comércio Internacional; American Arbitration Association - AAA, London Court of Arbitration; a Câmara de Comércio de Estocolmo, entre outras. Tem-se também, a Câmara de Comércio do Mercosul e Américas; Câmara de Comércio de Tóquio e o Tribunal Arbitral da Bolsa de Comércio de Buenos Aires, entre outras. Geralmente, as Cortes arbitrais não julgam, os árbitros são quem julgam, em operações sigilosas, tecnicamente especializadas, em locais neutros e a menor custo (BREGALDA, 2007, p. 246).

Os princípios que norteiam a arbitragem transnacional são: princípio da autonomia da vontade, ou seja, as partes escolhem o que lhes é razoável em solução de conflitos presentes ou futuros relativos a contratos e negócios; princípio da boa-fé, ou seja, escolhida a arbitragem não podem criar óbices; princípio do devido processo legal assegurando obediência a regras procedimentais e ao contraditório; princípio da imparcialidade do árbitro; princípio do livre convencimento do árbitro; princípio da autonomia da cláusula compromissória, ou seja, eventuais nulidades no contrato não afetam a cláusula compromissória de resolver o conflito por arbitragem; princípio da competência, ou seja, o árbitro se torna competente para resolver o conflito em matéria de existência, validade e eficácia da convenção de arbitragem (BREGALDA, 2007, p. 247).

A tutela jurisdicional das nações fica, em princípio, excluída quanto ao exame de mérito, pois constituída a modelagem alternativa de solução de conflitos sempre que os direitos em confronto sejam disponíveis. Este fator é bem positivo e dilui os custos transacionais pela ótica da análise econômica do direito. Neste particular Cooter e Uelen sintetizando o "Teorema de Coase" lembram: "quando os custos de transação são suficientemente altos para impedir a negociação, o uso eficiente dos recursos dependerá da maneira como os direitos de propriedade são atribuídos" (COOTER; UELEN, 2010, p. 103). Assim, o Poder Judiciário sabe a importância da arbitragem no Brasil, conforme o julgamento do Recurso Especial número 1.331.100 - BA, pelo Superior Tribunal de Justiça, do Brasil, preza-se o convívio harmônico dos juízos arbitrais com os órgãos do Judiciário como "ponto fundamental ao prestígio da arbitragem” (BRASIL, 2015). 
Muitos alunos saem da graduação sem saber como funcionam as cortes arbitrais internacionais. Assim, na primeira parte deste artigo trilhando por uma abordagem descritiva será apreciada a operacionalidade das principais cortes arbitrais internacionais, para a constatação de seus modi operandi, bem como, semelhanças, por tradução própria:

\section{Quadro 1. A Arbitragem no Internacional Centre for Settlement of Investiment Disputes - ICSID (Banco Mundial)}

\begin{tabular}{|c|c|}
\hline Detalhes & Disposições Legais \\
\hline Compromisso arbitral & $\begin{array}{l}\text { Embora o consentimento das partes seja uma condição } \\
\text { essencial para a jurisdição do Centro, consentir por si só não } \\
\text { será suficiente para trazer uma disputa dentro de sua jurisdição. } \\
\text { Em consonância com o objetivo da Convenção, a jurisdição do } \\
\text { Centro é ainda limitada pela referência à natureza do litígio e } \\
\text { respectivas partes. Eventual investidor pode dar o seu } \\
\text { consentimento ao aceitar a oferta de arbitramento por escrito } \\
\text { (artigos } 22 \text { a 25). A Convenção está sujeita a ratificação, } \\
\text { aceitação ou aprovação pelos Estados signatários de acordo } \\
\text { com seus procedimentos constitucionais (Artigo 68), o termo } \\
\text { "competência do Centro" é usado na Convenção como uma } \\
\text { expressão conveniente para significar limites dentro dos quais } \\
\text { as disposições da Convenção serão aplicadas e as instalaçães } \\
\text { do Centro ficarão disponíveis para processos de conciliação e } \\
\text { arbitragem sobre investimentos. }\end{array}$ \\
\hline Requerimento & $\begin{array}{l}\text { O requerimento de arbitragem deve ser encaminhado para o } \\
\text { Secretário-Geral do ICSID. }\end{array}$ \\
\hline Local & $\begin{array}{l}\text { Em princípio processo de conciliação e arbitragem será } \\
\text { realizado na sede do Centro. Porém, se as partes assim } \\
\text { acordarem, na sede do Tribunal Permanente de Arbitragem ou } \\
\text { de qualquer outra instituição apropriada, seja privada ou } \\
\text { pública, o Centro poderá tomar medidas cabíveis a esse fim; ou } \\
\text { ainda, em qualquer outro local aprovado pela Comissão ou } \\
\text { Tribunal, após consulta com o Secretário-Geral (artigos } 62 \text { e } \\
\text { 63). }\end{array}$ \\
\hline Custos & $\begin{array}{l}\text { Todos os pagamentos, incluindo reembolso de despesas, para } \\
\text { todos os casos serão feitas pelo Centro e não através de } \\
\text { qualquer das partes no processo; serão pagas a membros de } \\
\text { Comissões, Tribunais e comitês; testemunhas e peritos } \\
\text { convocados por iniciativa de uma Comissão, Tribunal ou da } \\
\text { Comissão, e não de uma das partes; membros do Secretariado } \\
\text { do Centro, incluindo as pessoas (tais como intérpretes, } \\
\text { tradutores, repórteres ou secretários) especialmente contratada } \\
\text { pelo Centro de um processo especial; o anfitrião de qualquer } \\
\text { procedimento realizado fora da sede do Centro nos termos do } \\
\text { artigo } 63 \text { da Convenção. Em princípio, com pagamentos } \\
\text { antecipados para o Centro cobrem os custos: logo que a }\end{array}$ \\
\hline
\end{tabular}




\begin{tabular}{|c|c|}
\hline & $\begin{array}{l}\text { Comissão ou Tribunal for constituído, o secretário-geral, após } \\
\text { consulta com o Presidente do organismo incorrida pelo Centro } \\
\text { antecipando os custos dos próximos três a seis meses, em } \\
\text { procedimentos individuais (Capítulo III, Regulamento 14). }\end{array}$ \\
\hline Árbitro $a d h o c$ & $\begin{array}{l}\text { O Centro admite nomeação de Comitê ad hoc nomeado a partir } \\
\text { do Painel de Árbitros nos termos do artigo 52(3) da } \\
\text { Convenção. O presidente, a pedido de qualquer das partes, e } \\
\text { após consulta ambas as partes, tanto quanto possível, pode } \\
\text { designar o árbitro ou árbitros ainda não nomeados. As partes } \\
\text { são livres para nomear conciliadores e árbitros de fora dos } \\
\text { Painéis fornecidos. Porém, os árbitros nomeados pelo } \\
\text { Presidente da Comissão nos termos do presente artigo não } \\
\text { deverão ser nacionais do Estado parte Contratante, ou do } \\
\text { Estado contratante cujo nacional for uma das partes na } \\
\text { controvérsia, para composição do Tribunal arbitral. }\end{array}$ \\
\hline Árbitro institucional & $\begin{array}{l}\text { Como visto acima, o Centro tem um painel de árbitros } \\
\text { catalogados para formação de Comitês, em princípio ad hoc. } \\
\text { Porém, o Secretário-Geral, os vice-secretários-gerais e os } \\
\text { membros do pessoal não podem servir no painel de } \\
\text { conciliadores ou de árbitros, ou como membros de qualquer } \\
\text { comissão ou ao tribunal, o que significa que outros árbitros } \\
\text { podem ter algum vínculo institucional e serem indicados. }\end{array}$ \\
\hline $\begin{array}{l}\text { Possibilidade de Recursos contra } \\
\text { a Sentença }\end{array}$ & $\begin{array}{l}\text { Há possibilidade de ser avençado que a decisão não } \\
\text { comportará recurso (artigo 26). Mas, contra a sentença cabe } \\
\text { interpretação, revisão ou anulação de uma decisão devem ser } \\
\text { dirigidas por escrito ao secretário-geral. Os recursos previstos } \\
\text { são de revisão (Artigo 51) e anulação (Artigo 52). A parte pode } \\
\text { pedir ao tribunal, em caso de omissão, para decidir qualquer } \\
\text { questão submetida para complementar a sua atribuição (Artigo } \\
\text { 49); poderá solicitar à interpretação da sentença (Artigo 50). Se } \\
\text { for o caso de anular a sentença, novo Tribunal será formado } \\
\text { para julgar o recurso. Nos termos do artigo } 52 \text { da convenção } \\
\text { qualquer uma das partes pode solicitar a anulação da sentença } \\
\text { através de requerimento, por escrito, dirigido ao Secretário- } \\
\text { Geral sobre um ou mais dos seguintes fundamentos: que o } \\
\text { Tribunal não foi devidamente constituído; que o Tribunal tenha } \\
\text { manifestamente excedido os seus poderes; que houve } \\
\text { corrupção por parte de um membro do Tribunal; se houve um } \\
\text { grave desvio de regra fundamental do procedimento; ou que a } \\
\text { atribuição não foi capaz de indicar os motivos em que se } \\
\text { baseou para decidir. }\end{array}$ \\
\hline Decisão definitiva & $\begin{array}{l}\text { A Sentença definitiva será assinada pelos membros do } \\
\text { Tribunal Arbitral. }\end{array}$ \\
\hline Obrigatoriedade & $\begin{array}{l}\text { A doutrina da imunidade soberana pode impedir a execução } \\
\text { forçada de um Estado. Mas, os Estados Contratantes podem } \\
\text { equacionar que a sentença proferida, nos termos da Convenção } \\
\text { com um julgamento final, seja executada em seus próprios }\end{array}$ \\
\hline
\end{tabular}




\begin{tabular}{|l|l|}
\hline Executoriedade & tribunais (artigo 43). A boa fé tem sido a prática. \\
\hline $\begin{array}{l}\text { Cada Estado Contratante reconhece a sentença proferida nos } \\
\text { termos da presente Convenção, com a obrigação de fazer } \\
\text { cumprir as obrigações pecuniárias impostas na sentença } \\
\text { arbitral em seus territórios, como uma espécie de execução em } \\
\text { julgamento final por um Tribunal do Estado membro, mediante } \\
\text { cópia autenticada da sentença obtida junto ao Secretário-Geral. } \\
\text { A Execução da sentença será regida pelas leis referentes à } \\
\text { execução de decisões em vigor no Estado cujo território a } \\
\text { execução é requerida (artigo 54). }\end{array}$ \\
\hline
\end{tabular}

Fonte: ICSID (BOUTIQUE INTERNATIONAL ARBITRATION LAW FIRM, 2014).

Quadro 2. Arbitragem na Internacional Chamber of Commerce - ICC (ONG Francesa)

\begin{tabular}{|l|l|}
\hline Detalhes & Disposições Legais \\
\hline Compromisso arbitral & $\begin{array}{l}\text { As partes se comprometem a cumprir qualquer ordem } \\
\text { proferida pelo tribunal arbitral (artigo 22, 5) ou a se submeter } \\
\text { ao procedimento de mediação (artigo 2 }{ }^{\circ} \text { ). }\end{array}$ \\
\hline Requerimento & $\begin{array}{l}\text { O início da arbitragem se conta do recebimento do do } \\
\text { Requerimento pela Secretaria. O Requerimento deverá conter } \\
\text { as seguintes informações: as qualificações das partes e de seus } \\
\text { representantes para efeito de arbitragem; circunstâncias em } \\
\text { litígio, origem e fundamentos; especificação do pedido com } \\
\text { estimativa de valores e projeções; quais contratos são } \\
\text { relevantes; quais convenções de arbitragem estão envolvidas; } \\
\text { proposta de números de árbitros e eventual escolha destes; } \\
\text { juntardocumentos; pagar a taxa fixada (custas e honorários da } \\
\text { arbitragem). }\end{array}$ \\
\hline Local & $\begin{array}{l}\text { Quando uma audiência tiver de ser realizada o tribunal arbitral } \\
\text { deverá, com razoável antecedência, notificar as partes para } \\
\text { comparecerem na data e no local que determinar (artigo 26, 1). } \\
\text { Tudo confidencial (artigo 6 }{ }^{\circ} \text { ). A Corte fixará o idioma do } \\
\text { arbitramento. }\end{array}$ \\
\hline Árbitro $a d$ hoc & $\begin{array}{l}\text { Após o recebimento do Requerimento o Secretário Geral } \\
\text { poderá solicitar ao requerente que faça um adiantamento da } \\
\text { provisão para os custos da arbitragem em valor suficiente. O } \\
\text { valor da provisão deverá ser suficiente para cobrir os } \\
\text { honorários e despesas dos árbitros, bem como, as despesas } \\
\text { administrativas da CCI relativas às demandas que lhe tenham } \\
\text { sido submetidas pelas partes (artigo 37). A remuneração dos } \\
\text { árbitros pode ser inferior ou superior à tabela remuneratória em } \\
\text { vigor, conforme o caso concreto (artigo 38). Os custos } \\
\text { administrativos obedecem a uma tabela escalonada pelo } \\
\text { patamar dos valores envolvidos (artigo 2, página 92). }\end{array}$ \\
\hline $\begin{array}{l}\text { As partes podem indicar árbitros à CCI (artigo 13); podem ser } \\
\text { aceitos desde que prestem declarações de imparcialidade e } \\
\text { independência. }\end{array}$ \\
\hline
\end{tabular}




\begin{tabular}{|c|c|}
\hline Árbitro institucional & $\begin{array}{l}\text { A CCI pode nomear árbitro que julgar competente para } \\
\text { examinar a matéria (artigo 13); deve seguir as normas } \\
\text { estabelecidas para nomear árbitros e mediadores } \\
\text { independentes; podem ser árbitro único, ou em três árbitros a } \\
\text { montagem do Tribunal Arbitral. Se for necessário nomear } \\
\text { árbitro de emergência, cabe ao Presidente nomear, salvo se os } \\
\text { autos já estiverem com o Tribunal Arbitral. Mesmo assim, } \\
\text { eventual árbitro emergencial para poder atuar deve assinar } \\
\text { declaração de aceitação, disponibilidade, imparcialidade e } \\
\text { independência (artigo 2, 5); a nomeação deste árbitro pode ser } \\
\text { impugnada. Pode ser nomeado um ou mais Mediadores } \\
\text { também (mediadores são terceiros neutros que auxiliam na } \\
\text { construção da conciliação). As partes podem deliberar não } \\
\text { querer árbitro de emergência (arbitragem expedita). Salvo } \\
\text { acordo escrito em contrário de todas as partes, o Mediador não } \\
\text { deverá estar atuando ou ter atuado em qualquer processo } \\
\text { judicial, arbitral ou similar relacionado com a disputa ou que } \\
\text { tenha sido objeto do Procedimento previsto no Regulamento, } \\
\text { na qualidade de juiz, árbitro, perito, representante ou consultor } \\
\text { de uma das partes. Os peritos serão independentes e assinarão } \\
\text { declaração de imparcialidade e independência. }\end{array}$ \\
\hline $\begin{array}{l}\text { Possibilidade de Recursos contra } \\
\text { Sentença }\end{array}$ & $\begin{array}{l}\text { O Tribunal Arbitral antes de sentenciar pode exigir garantia } \\
\text { para decidir sobre pedido de medida cautelar que, inclusive, } \\
\text { pode ser decidida sob a forma de sentença arbitral. Nenhuma } \\
\text { sentença arbitral poderá ser proferida pelo tribunal arbitral } \\
\text { antes de ter sido aprovada quanto à sua forma pela Corte. Toda } \\
\text { sentença arbitral obriga as partes. Ao submeter o litígio à } \\
\text { arbitragem segundo o Regulamento, as partes comprometem- } \\
\text { se a cumprir a sentença arbitral sem demora e renunciam a } \\
\text { todos os recursos a que podem validamente renunciar. A } \\
\text { decisão de corrigir ou de interpretar a sentença arbitral deverá } \\
\text { ser proferida sob a forma de um addendum, que constituirá } \\
\text { parte integrante da sentença arbitral (artigo 36). No entanto, } \\
\text { admite acordo. }\end{array}$ \\
\hline Decisão definitiva & $\begin{array}{l}\text { Não cabe recurso, a sentença do Tribunal Arbitral é definitiva } \\
\text { (artigo 35). A sentença arbitral final fixará os custos da } \\
\text { arbitragem e decidirá qual das partes arcará com o seu } \\
\text { pagamento, ou em que proporção serão repartidos entre as } \\
\text { partes, honorários, despesas em aberto, etc. }\end{array}$ \\
\hline Obrigatoriedade & $\begin{array}{l}\text { As partes se comprometem a cumprir qualquer ordem } \\
\text { proferida pelo tribunal arbitral (artigo } 22) \text {. }\end{array}$ \\
\hline Executoriedade & $\begin{array}{l}\text { Não havendo acordo, se não for cumprida a sentença arbitral } \\
\text { poderá ser executada no foro competente, para a execução. A } \\
\text { CCI busca assegurar que a execução seja realizada. }\end{array}$ \\
\hline
\end{tabular}

Fonte: CCI (CÂMARA DE COMÉRCIO INTERNACIONAL, 2017).

Quadro 3. Arbitragem no International Centre for Dispute Resolution (ICDR - AAA) 


\begin{tabular}{|c|c|}
\hline Detalhes & Disposições Legais \\
\hline Compromisso arbitral & $\begin{array}{l}\text { Para poder notificar a parte para arbitragem sobre o contrato, ou } \\
\text { contratos atingidos, há que se ter previsão de cláusula arbitral } \\
\text { compromissória para controvérsia comercial internacional. }\end{array}$ \\
\hline Requerimento & $\begin{array}{l}\text { Considerar-se-á instituída a arbitragem na data em que o } \\
\text { Administrador receber a Notificação de Arbitragem e pode ser } \\
\text { online (www.icdr.org). A Notificação de Arbitragem deverá } \\
\text { conter as seguintes informações: o pedido para que a disputa } \\
\text { seja submetida à arbitragem; os nomes, endereços, números de } \\
\text { telefone, de fax, endereços eletrônicos das partes e, caso } \\
\text { conhecidos, também de seus advogados; cópia da cláusula } \\
\text { compromissória ou da convenção de arbitragem que se invoca e, } \\
\text { caso a demanda tenha por base mais de uma convenção ou } \\
\text { cláusula, cópia de todas elas; menção aos contratos dos quais se } \\
\text { originou o litígio ou aos quais se refira; descrição da demanda e } \\
\text { a indicação dos fatos que a embasam; descrição do pedido ou } \\
\text { reparação pleiteada e os montantes reclamados; e, } \\
\text { opcionalmente, a depender de qualquer acordo anterior entre as } \\
\text { partes, podem ser incluídas propostas com relação à forma de } \\
\text { designação, o número de árbitros, o lugar e o(s) idioma(s) da } \\
\text { arbitragem e eventual interesse em mediação. A Notificação de } \\
\text { Arbitragem deverá estar acompanhada do comprovante de } \\
\text { pagamento das respectivas custas de distribuição (artigo } 2^{\circ} \text { ). }\end{array}$ \\
\hline Local & $\begin{array}{l}\text { Reuniões para tentativa de composição podem ser realizadas em } \\
\text { quaisquer locais apropriados para audiências podendo ser } \\
\text { escolhidas pelas partes. O ICDR administra mecanismos de } \\
\text { solução de controvérsias em todo o mundo. Mediações e } \\
\text { arbitragens ICDR podem ser conduzidas em qualquer idioma à } \\
\text { escolha das partes. As audiências podem ser realizadas com } \\
\text { presença física, vídeo conferência, ou outro meio que o árbitro } \\
\text { considere adequado, em arbitragem expedita, ou sumária } \\
\text { (Regulamento, artigo E-9). }\end{array}$ \\
\hline Custos & $\begin{array}{l}\text { Salvo determinação distinta do mediador, o ICDR requererá às } \\
\text { partes que depositem antecipadamente à sessão de mediação, o } \\
\text { valor da quantia que depois de consultado o mediador este } \\
\text { julgar suficiente para cobrir os custos e despesas da mediação. O } \\
\text { ICDR preparará um relatório contábil às partes; eventual saldo } \\
\text { não utilizado será devolvido às partes, ao final da mediação } \\
\text { (artigo 15). Não há taxa de registro para se solicitar a mediação, } \\
\text { nem taxa para requerer ao ICDR que convide as partes à } \\
\text { mediação. Salvo acordo em contrário, as partes dividirão } \\
\text { igualmente os custos e as despesas da mediação (artigo 17). O } \\
\text { uso de salas para audiências de colheita de informações, de } \\
\text { medidas cautelares, correção da sentença, etc., são objetos de } \\
\text { pagamentos pelas partes. }\end{array}$ \\
\hline Árbitro ad hoc & $\begin{array}{l}\text { Se as partes não concordarem com nenhum dos mediadores } \\
\text { indicados na lista, ou se os mediadores aceitáveis não puderem } \\
\text { atuar ou, ainda, se por qualquer razão, a nomeação não puder ser } \\
\text { feita a partir da referida lista, o ICDR terá autonomia para fazer } \\
\text { a nomeação dentre outros membros do Quadro de Mediadores } \\
\text { do ICDR, sem necessidade de submeter listas adicionais (artigo }\end{array}$ \\
\hline
\end{tabular}




\begin{tabular}{|c|c|}
\hline & $\left.4^{\circ}\right)$ \\
\hline Árbitro institucional & 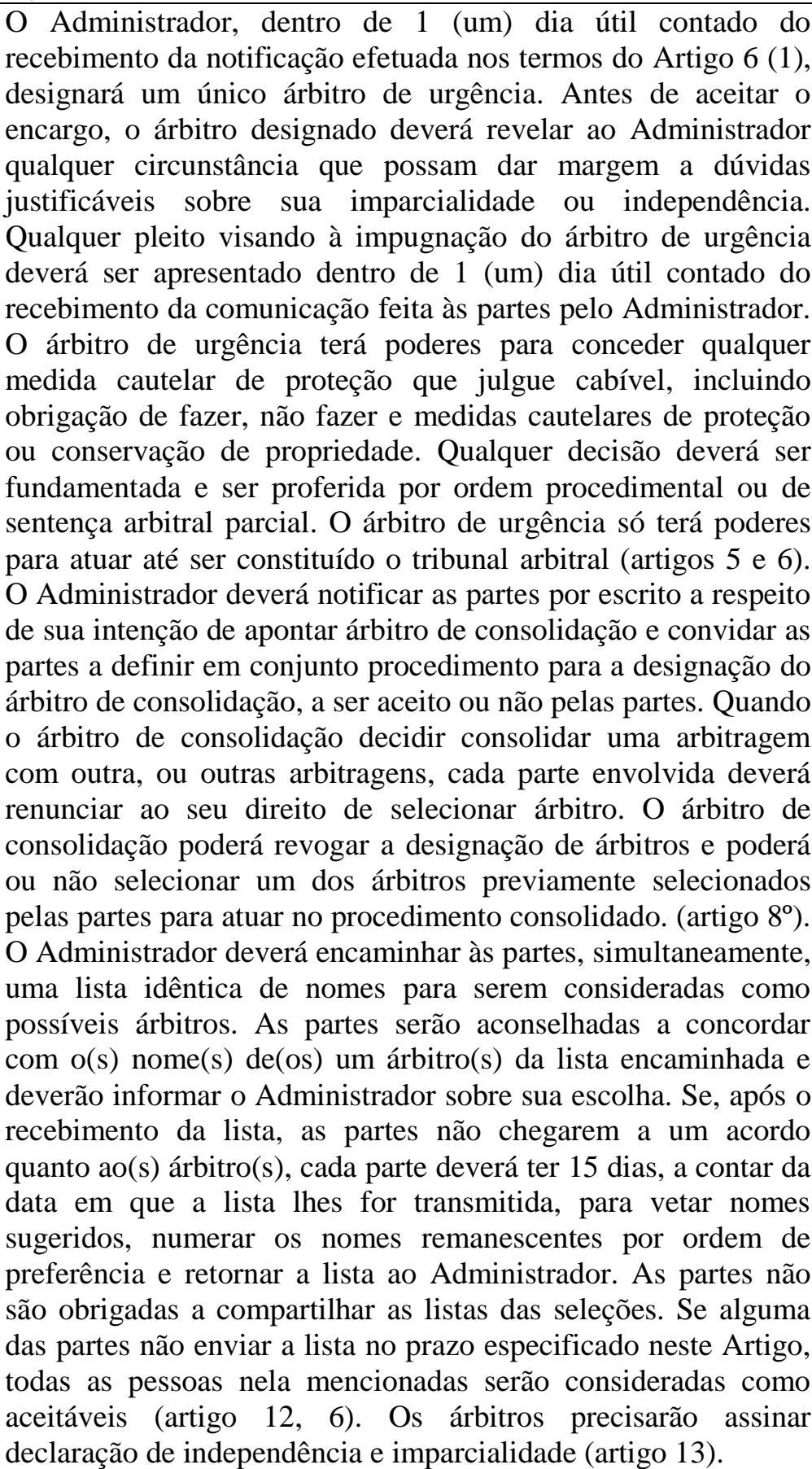 \\
\hline $\begin{array}{l}\text { Possibilidade de Recursos } \\
\text { contra Sentença }\end{array}$ & $\begin{array}{l}\text { Em } 30 \text { dias a contar do recebimento da sentença arbitral, } \\
\text { qualquer parte, mediante ciência das partes, poderá requerer ao } \\
\text { tribunal arbitral que interprete a sentença arbitral ou corrija } \\
\text { qualquer erro material, tipográfico ou de cálculo ou, ainda, } \\
\text { requerer que o tribunal arbitral adite a sentença arbitral em } \\
\text { relação a reconvenções ou pedidos de compensação } \\
\text { apresentados; o tribunal de ofício, ou em até } 30 \text { dias, decidirá. } \\
\text { As partes serão responsáveis por todos os custos associados. }\end{array}$ \\
\hline Decisão definitiva & $\begin{array}{l}\text { As partes podem transigir. Havendo decisão definitiva, as partes } \\
\text { comprometem-se a cumprir de imediato a sentença arbitral e, na } \\
\text { falta de disposição em contrário, renunciam, na medida em que }\end{array}$ \\
\hline
\end{tabular}




\begin{tabular}{|l|l|}
\hline & $\begin{array}{l}\text { seja permitido renunciar validamente, de forma irrevogável, ao } \\
\text { direito a qualquer forma de recurso, revisão ou apelação a } \\
\text { qualquer corte ou outra autoridade judicial. O tribunal deverá } \\
\text { motivar a sentença arbitral, salvo se as partes acordarem que tal } \\
\text { motivação seja desnecessária (artigo 30). }\end{array}$ \\
\hline Obrigatoriedade & $\begin{array}{l}\text { As partes comprometem-se a cumprir de imediato a sentença } \\
\text { arbitral. Se a lei de arbitragem aplicável exigir que a mesma seja } \\
\text { arquivada ou registrada, o tribunal deverá cumprir tal requisito } \\
\text { artigo 30). }\end{array}$ \\
\hline Executoriedade & $\begin{array}{l}\text { Apesar das partes renunciarem qualquer recurso no âmbito do } \\
\text { ICDR e até deixar de judicializar posteriormente a questão } \\
\text { arbitrada (artigo 30), pacta sunt servanda, em caso de não } \\
\text { cumprimento, possivelmente, a questão passa ser objeto de } \\
\text { questionamento judicial. Afinal, nos termos do artigo 174, do } \\
\text { Código de Bustamante, a presunção de coisa julgada por } \\
\text { sentença estrangeira será admissível, sempre que a sentença } \\
\text { reunir as condições necessárias para a sua execução no território } \\
\text { nacional. }\end{array}$ \\
\hline
\end{tabular}

Fonte: ICDR - AAA (INTERNATIONAL CENTRE FOR DISPUTE RESOLUTION, 2014).

Desta forma, os principais conceitos vão se tornando cada vez mais familiarizados por parte dos operadores do direito quanto à arbitragem internacional. Na esfera doméstica brasileira, no entanto, algumas providências se fazem necessárias quanto às sentenças arbitrais estrangeiras: ratificação de tratado no direito interno, arbitragem sobre direitos disponíveis (que se possa transacionar voluntariamente); previsão contratual; local neutro e sob sigilo; compromisso arbitral (clausula em que as partes se comprometem a se submeter a um procedimento arbitral); pacta sunt servanda (os acordos devem ser cumpridos); procedimento do julgamento; prazo; órgão julgador; revelia; critério de decisão; julgamento por equidade (solução justa), ou a critério das partes; princípios gerais de direito; executividade da sentença; sentença estrangeira arbitral, custas e despesas de arbitramento e recursos.

Por mais rápido e fascinante que seja o instituto da arbitragem internacional diante da economia digital, toda esta realidade arbitral fica praticamente invisível às jurisdições estatais. Sabe-se, que a competição dos negócios internacionais tende a ser cada dia mais acirrada, e com isso, surge também a competição tributária internacional, ou guerra fiscal internacional, o que pode enfraquecer e inviabilizar parte do desenvolvimento de nações pobres. O fenômeno da elisão fiscal internacional, segundo Moreira Júnior, pode ocorrer quando o "contribuinte evita aplicar determinada norma ou conjunto de normas por meio 
de atos que impedem a ocorrência do fato gerador da obrigação tributária colocando-se sob a égide de outro sistema jurídico mais favorável” (MOREIRA JÚNIOR, 2003, p. 221).

Os tratados internacionais contra a bitributação, segundo Bomtempo, encontram-se obsoletos diante do fenômeno do e-commerce. A realidade dos "paraísos fiscais" seduzem as empresas a operarem com se utilizando desses locais de tributações favorecidas. As operações transfronteiriças, via e-commerce, romperam com os modelos fiscais tradicionais fincados na materialidade (mercadorias, faturas, intermediários, entre outros). As chances de evasão fiscal se tornaram imensas, com manobras típicas como treaty shopping, manipulação de preços de transferências, subfaturamentos e superfaturamentos, movimentações de capitais por locais de tributações favoráveis (BOMTEMPO, 2016, p. 96). Se os Estados nacionais se fragilizarem não haverá como alcançarem estabilizações políticas, econômicas e desenvolvimento sustentável.

O World Bank Group (2020) estima que o estoque das dívidas públicas mundiais esteja próximo ao patamar de U\$ 253 trilhões de dólares e o PIB Mundial está na faixa de US\$ 80 trilhões de dólares ano. Pelo tamanho do PIB Mundial e o tamanho do estoque de dívidas públicas dá para se perceber o volume de investimentos e negócios internacionais, bem como, o volume de títulos transacionais e derivados. Segundo Cristensen, Coleman e Kapoor, o governo do Reino Unido estima que 60\% do comércio internacional se dão entre empresas transnacionais (CRISTENSEN, COLEMAN E KAPOOR, 2004). Possivelmente, esteja nesta realidade mais uma razão para o ideal de harmonização dos procedimentos arbitrais. Cada vez mais o grande poder de influência dos negócios transnacionais diluem as soberanias das nações. Muitos trilhões de dólares em negócios passam por paraísos fiscais, em operações envolvendo várias jurisdições on-line (BOMTEMPO, 2016, p. 118).

James Henry estimou algo em torno de US 21 A 32 trilhões de dólares sediados em paraísos fiscais, em 2010: "a significant fraction of global private financial wealth - by our estimates, at least $\$ 21$ to $\$ 32$ trillion as of 2010 - has been invested virtually tax-free through the world's still expanding black hole of more than 80 'offshore' secrety jurisdicions" (HENRY, 2012, p. 5). As empresas transnacionais necessitam de soluções mais flexíveis e menos burocráticas na realidade atual. A burocracia estatal pode complicar os negócios e pode impor custos transacionais. É um desafio. Um governo soberano, em princípio, "não se subordina a qualquer autoridade que lhe seja superior, não reconhece, em última análise, nenhum poder maior de que dependam a definição e o exercício de suas competências" (REZEK, 2011, p. 259). 
Eventuais impasses, entre negociadores internacionais, em jurisdições diversas, podem não ser perceptíveis levando a perdas de arrecadação tributárias. Tanzi observa que o dinheiro pode migrar em tempo real para os "paraísos fiscais" movimentando trilhões de dólares americanos, o que dilui a arrecadação de impostos, principalmente, o imposto de renda. Mas, o progresso exige rapidez. Por este breve extrato pode-se observar a magnitude dos valores confiados à arbitragem internacional na economia virtual, o que, possivelmente, induz haver alguma conexão com o sigilo das arbitragens, pois os interesses em jogo não são pequenos: segurança operacional, planejamento e proteção tributária e liberdade de transacionar em relação às normas estatais.

\section{A ARBITRAGEM CHEGOU NO BRASIL}

A arbitragem, segundo Teixeira (1996), vem evoluindo desde as origens históricas de Roma. Depois passou a ser estatal a solução dos conflitos em Roma e foi mitigado no civil law. No entanto, encontrou razoável utilidade no common law norte-americano. A arbitragem é vastamente utilizada no comércio internacional. O Brasil conhece a arbitragem desde a época da colonização portuguesa.

O arbitramento foi bem utilizado desde o Império, segundo Lobo (2020), nas concessões de ferrovias, pelo Barão de Rio Branco, visando ampliar as fronteiras nacionais. O Brasil aderiu ao Código de Bustamante em 1.928, que foi internalizado sob o Decreto 18.871, de 1929 (Código de Derecho Internacional Privado). Mais recentemente, a Convenção de Nova Iorque, de 1.958, das Nações Unidas, garantiu eficácia às cláusulas compromissórias arbitrais estrangeiras e às execuções de sentenças estrangeiras. Na prática, presume-se válido o compromisso arbitral que deu lastro à sentença oriunda de um contrato internacional, com base no protocolo relativo a cláusula de arbitragem que o Brasil se vê signatário, desde o Decreto n. 21.187, de 1932 editado por Getúlio Vargas e firmado em Genebra, em 1923, pelos “Estados Unidos do Brasil”. Neste Decreto ficou reconhecida a validade da cláusula arbitral, a facilitação da tramitação processual, garantia de execução, entre outras cláusulas protocolares.

O modelo de arbitragem comercial - a Lei Modelo, de 1985, da United Nations Comission for Internacional Trade Law (Comissão das Nações Unidas para a Legislação Comercial Internacional - UNCITRAL) reforçou o despertar recente da arbitragem no Brasil (MANGE, 2014, p. 30 e 31). O Brasil é signatário do Tratado do Mercosul e da 
corte arbitral do MERCOSUL, cuja norma internalizada se deu pela edição do Decreto Federal n. 4.719, de 2003 (BRASIL, 2003), que segue a tipologia das demais cortes arbitrais internacionais, como se verá à frente.

Empresários e advogados ligados ao Instituto Liberal de Pernambuco, em 1989, segundo Engelmann (2012), lançaram um movimento para encaminhar, perante o Congresso Nacional, um anteprojeto de lei de arbitragem; em novembro de 1991 ocorreu a adesão da FIESP, de professores da USP e de juristas. Surgiu o Projeto de Lei, de iniciativa do Senado, n. 78, de 1992. Mais a frente foi editada a Lei 9.307, de 1996. Nesta Lei da Arbitragem há uma distinção entre a sentença arbitral doméstica e a sentença arbitral estrangeira.

No mais, a Lei 9.307, de 1996 sem seus aspectos gerais procedimentais segue o padrão internacional: a) cláusula compromissória (artigos $3^{\circ}, 4^{\circ} 6^{\circ}$ e $7^{\circ}$ ); b) Requerimento do juízo arbitral; c) pode-se constituir árbitro ad hoc ou árbitro institucional; d) há possibilidade de recorrer: Se for necessário alcançar medida de urgência, de natureza cautelar deferida pelo árbitro será necessário a atuação de juiz togado na fase preparatória. Prolatada a sentença arbitral, no prazo de 5 (cinco) dias, a contar do recebimento da notificação, ou da ciência pessoal da sentença arbitral, pode a parte interessada pedir que se corrija erro material, esclareça obscuridade, dúvida, omissão ou contradição da sentença arbitral. A decisão deverá ser prolatada em 10 dias. Será nula a sentença arbitral se nula a convenção de arbitragem, se emanar de quem não poderia ser árbitro, não obedecer as formalidades da lei, se houver prevaricação, concussão ou corrupção passiva, entre outras hipóteses do artigo 32. A parte prejudicada pode suscitar perante o Poder Judiciário a nulidade parcial ou total da sentença arbitral. Mas, também, cabe impugnação na fase de cumprimento da sentença. Em caso de persistir omissões mesmo em nova sentença arbitral, o Poder Judiciário pode decidir de forma complementar (artigo 33). Muito raramente tem sido possível alterar uma sentença arbitral no Brasil. A sentença arbitral tem força de título executivo.

A arbitragem permite que impasse sobre direitos disponíveis encontrem soluções mais rápidas. Não se possibilita atuação arbitral em direitos indisponíveis, ou que a presença do Ministério Público seja obrigatória. Importante registrar que a arbitragem não tem natureza jurisdicional, como bem lembram Marinoni, Arenhart e Mitidiero, citando Chiovenda, mas pode solucionar controvérsias por critérios legais e de equidade (MARINONI, 2015, p. 486). 
Por outro lado, nos termos dos artigos 22-A e 22-B, da Lei 9.307, de 1996, com as alterações da Lei 13.129, de 2015, as partes podem recorrer ao Poder Judiciário para alcance de medida cautelar, ou de urgência, antes de instituir a arbitragem. Esta eventual liminar tem cessada sua vigência se a parte não requerer a arbitragem em 30 dias. Uma vez instituída a arbitragem o árbitro pode manter, ou não, a liminar concedida pelo Poder Judiciário, ou mesmo, examinar novos pedidos de urgência. Os árbitros, no Brasil, nos termos do julgamento do Recurso Especial n. 1.481.644-SP, não têm "poder de império", ou seja, não têm "poder coercitivo" (BRASIL, 2021). Não havendo cumprimento espontâneo das decisões arbitrais, em princípio, pode restar ao Estado-juiz impor força executória à decisão arbitral se válida. Afinal, o Estado "reclama com êxito o monopólio legítimo da coação física para a manutenção das ordenações” (WEBER, 2010, p. 104).

Atualmente o instituto da arbitragem no Brasil guarda semelhanças com a arbitragem internacional. A vontade manifesta e devidamente compromissada pode conduzir à eleição até de uma corte internacional para solução de determinado conflito de interesse de natureza internacional. Contudo, no Brasil, por força dos artigos 9 e 12, da Lei de Introdução às Normas Brasileiras existem ressalvas. Será competente a autoridade judiciária brasileira nas seguintes situações: onde foram constituídas as obrigações em território nacional; ou se o réu for domiciliado no País; se estipulada a obrigação para ser cumprida no Brasil. Ainda, nos termos do parágrafo $2^{\circ}$, do artigo $2^{\circ}$, da Lei 9.307, de 1996, permite convencionar a arbitragem com base nos princípios gerais de direito, usos e costumes e nas regras internacionais de comércio.

Neste particular, houve o julgamento de um Conflito de Competência n. 139.519 - RJ perante o Superior Tribunal de Justiça - STJ, questionando a possibilidade de determinada controvérsia no setor petrolífero brasileiro ser julgada pelo Poder Judiciário e não pela Internacional Chamber of Commerce - ICC (Câmara de Comércio Internacional CCI), em razão de cláusula compromissória presente em contrato de concessão. Depois de 16 anos de contrato, por intervenção da agência reguladora surgiram novos impactos financeiros sobre a avença (fato do príncipe). Diante do conflito suscitado pela empresa estatal de petróleo, o STJ julgou que a "jurisdição arbitral precede a jurisdição estatal” (...) "para solucionar litígios que tenham por objeto direitos patrimoniais disponíveis", assim, foi declarada competente a referida Corte arbitral eleita para julgar a questão (BRASIL, 2017). 
A tendência que se vislumbra é a ampliação da utilização da arbitragem no Brasil, ao lado dos juizados especiais, de forma a aliviar o Poder Judiciário em matérias ligadas à Administração Pública, em acordos envolvendo executivos na Justiça do Trabalho, relações de consumo e negócios entre empresas. A maioria das normas das nações sobre arbitragem, inclusive no Brasil, concedem boa autonomia às partes e árbitros quanto a regras de condução dos processos arbitrais.

A competência para homologar sentença estrangeira no Brasil é do Superior Tribunal de Justiça - STJ, nos termos da alínea “i”, do inciso I, do art. 105, da Constituição Federal de 1988, com o advento da Emenda Constitucional n. 45, de 2004, do artigo 960, e seguintes, do Novo CPC. Há que ser observado, em especial, o artigo 963, do NCPC. Hão que serem obedecidos, também, os requisitos dos artigos 216-A a 216-X, do Regimento Interno do STJ (RISTJ) e a Resolução n. 9, de 2005, do STJ. Recolhimentos de custas, o feito tramita via peticionamento eletrônico.

Se o requerente apresentar a anuência da instituição requerida, a tramitação se dá mais rapidamente, pois a citação por carta rogatória pode demorar muito; para envio de uma rogatória pode ser necessário tradução juramentada, documentação impressa, entre outras formalidades. Homologada a sentença estrangeira a Justiça Federal é competente para sua execução.

Todavia, em caso de contestação do pedido de homologação, as disposições do art. 38, da Lei 9.307, de 1996, podem dar suporte à impugnação. Ouvida a ProcuradoriaGeral da República, o feito será julgado pela Corte Especial, com os recursos previstos Resolução n. 9, de 2005, do STJ. Indeferido o pedido de homologação, a parte interessada ainda pode renovar o pedido de homologação se corrigir o requisito insatisfeito, nos termos do art. 40, da Lei 9.307, de 1996. Interessante observar, com base no julgamento do Recurso Especial n. 934.771-SP, foi considerado, neste julgamento, que o instituto da arbitragem tem natureza eminentemente processual pelo Superior Tribunal de Justiça, as disposições da Lei 9.307, de 1996 têm incidência até mesmo frente a contratos anteriores a esta lei se neles constar cláusula arbitral (BRASIL, 2010). O compromisso arbitral é cláusula vinculativa obrigatória.

Houve uma Sentença Estrangeira Contestada, n. 14.679 - PT, envolvendo a disputa entre uma empresa de produtos eletrônicos e uma indústria naval brasileira, em contrato firmado no Brasil. A empresa de produtos eletrônicos pediu a homologação de uma sentença prolatada em Paris, pela corte arbitral Câmara de Comércio Internacional. 
Em contestação foi arguida a nulidade de uma cláusula contratual. Porém, como todos os requisitos legais haviam sido obedecidos estribando a referida sentença, não foi analisado o mérito do julgamento, pois revestida de legalidade. Assim, a sentença estrangeira foi homologada (BRASIL, 2017).

Preenchidos os requisitos legais, o STJ homologa a sentença estrangeira. Em regra, não se examina o mérito relativo à disputa internacional após sentenciada, salvo "dentro de estreitos limites, verificar eventual ofensa à ordem pública e à soberania nacional" (BRASIL, 2017). Nos tribunais estaduais, também, a exemplo do julgamento do Processo n. 1.0024.07.549724-8/001 pelo Tribunal de Justiça do Estado de Minas Gerais, a existência de convenção de arbitragem, nesta linha, via de regra, enseja a extinção do processo oriundo de conflito de juízo arbitral sem julgamento de mérito (BRASIL, 2008). Desta forma, a velocidade com que o conflito tem seu fim faz com que o instituto da arbitragem seja estratégico para a grande parte dos litígios privados.

A quantidade de negócios realizados entre as próprias empresas transacionais no Brasil e no exterior é grande. Esta harmonização crescente dos procedimentos arbitrais amplia as potencialidades dos negócios na globalização permitem redução dos custos transacionais e melhores lucros. A flexibilidade procedimental dos árbitros confere a tendência destes arbitramentos se ampliarem, dada a grande influência do poder econômico na concorrência internacional e nacional, tornando-se indispensável aumentar a produtividade para o alcance de progresso e crescimento econômico.

\section{CONCLUSÃO}

A arbitragem internacional é um importante meio alternativo de solução de disputas negociais privadas, em direitos disponíveis. A Lei Modelo UNCITRAL dinamizou a padronização de procedimentos internacionais. Observa-se que os regulamentos arbitrais internacionais obedecem, praticamente, os mesmos procedimentos. Considerando a quantidade de culturas jurídicas existentes no Mundo, as empresas transnacionais realmente precisam de meios ágeis para solução de seus conflitos de interesses.

Tomando-se a inteligência do artigo 840, do Código Civil, se faz lícito aos interessados prevenirem ou terminarem litígios por acordos. As demoras de um processo jurisdicional são evitadas e as soluções consensuais, por vezes, são construídas. Nesta 
linha, desde que a arbitragem não ofenda a ordem pública ou a soberania nacional e que atenda a todos os requisitos legais, pode ser reconhecida uma sentença estrangeira no Brasil. Em princípio, não se examina o mérito, aspectos fiscais e morais. Há um trade-off entre a necessidade de velocidade na solução de controvérsias e deter a opacidade destas transações se existir algum interesse público envolvido ferido. No entanto, em termos econômicos e de celeridade há um ganhos de produtividade negociais impressionantes.

No entanto, quanto aos sigilos, sobretudo fiscais, há um direito fundamental à transparência internacional difuso em proteção dos Estados nacionais que não devem ser ultrapassados, sobretudo, em questões que envolvem o e-commerce. Salvo melhor juízo, esta realidade induz à confirmação satisfatória da hipótese: os valores transacionais são elevados, o que faz com que o sigilo das disputas arbitrais seja interessante às partes na economia global, há então, aspectos de velocidade desejável, produtividade, segurança operacional, garantia de liberdade em face dos órgãos de controle dos Estados nacionais e fator de proteção tributária relevantes, para que as transações sejam confidenciais. O instituto da arbitragem é eficiente, rápido e reduz os custos transacionais no cenário de globalização. Produtividade é progresso.

\section{REFERÊNCIAS}

BOMTEMPO, Eugênio Pacceli de Morais. E-Commerce, Tributação e Cultura: Análise juseconômica das imunidades tributárias sobre as cadeias produtivas de livros e músicas. Curitiba: Juruá, 2016.

BOUTIQUE INTERNATIONAL ARBITRATION LAW FIRM. As Regras de Arbitragem ICSID (A partir de junho 2014). Disponível em: <https://www.internationalarbitration-attorney.com/pt/icsid-arbitration-rules-current-june-2014/>. Acesso em: 2 jan. 2021.

BRASIL. Decreto n. 4.719, de 4 de junho de 2003. Promulga o Acordo sobre Arbitragem Comercial Internacional do Mercosul. Disponível em: <http://www.planalto.gov.br/Ccivil_03/decreto/2003/D4719.htm>. Acesso em: 10 jan. 2021.

BRASIL. Lei 9.307, de 23 de setembro de 1996. Dispõe sobre Arbitragem no Brasil. Disponível em: 〈http://www.planalto.gov.br/ccivil_03/leis/19307.htm>. Acesso em: 15 jan. 2021.

BRASIL. STJ. Corte Especial. Recurso Repetitivo. RESP 1102460 -RJ. Rel. Min. Marco Buzzi, j. 17 jun. 2015. Disponível em: 〈http://www.stj.jus.br〉. Acesso em: 2 mar. 2021. 
BRASIL. STJ. Corte Especial. SEC 16.180 - EX. Rel. Min. Benedito Gonçalves, j. 20 nov. 2017. Disponível em: <http://www.stj.jus.br>. Acesso em: 20 mar. 2021.

BRASIL. STJ. Corte Especial. SEC n. 14679 - EX. Rel. Min. Og Fernandes, j. 7 jun. 2017. Disponível em: <http://www.stj.jus.br>. Acesso em: 25 mar. 2021.

BRASIL. STJ. $4^{\text {a }}$ Turma. RESP n. 1.331.100 - BA. Rel. Min. Maria Isabel Galotti, j. 17 dez. 2015. Disponível em: <http://www.stj.jus.br>. Acesso em: 2 out.. 2021.

BRASIL. STJ. $4^{\text {a }}$ Turma. RESP n. 1.481.644 - SP. Rel. Min. Luis Felipe Salomão, j. 1 jun. 2021. Disponível em: <http://www.stj.jus.br>. Acesso em: 5 out. 2021.

BRASIL. STJ. $4^{\text {a }}$ Turma. RESP n. 934.771 - SP. Rel. Min. Luis Felipe Salomão, j. 25 mai. 2010. Disponível em: <http://www.stj.jus.br>. Acesso em: 8 out. 2021.

BRASIL. STJ. $1^{\text {a }}$ Seção. CC n. 139.519 - RJ. Rel. Min. Napoleão Nunes Maia Filho, j. 11 ou. 2017. Disponível em: <http://www.stj.jus.br>. Acesso em: 2 mar. 2021.

BRASIL. TJMG. Processo n. 1.0024.07.549724-8/001(1). Des. Rel. Nicolau Masselli, j. 2 abr. 2008. Disponível em: 〈http://www.tjmg.jus.br>. Acesso em: 26 mar. 2021.

BREGALDA, Gustavo. Direito Internacional Pública e Direito Internacional Privado. São Paulo: Atlas, 2007.

CALMON, Eliana. A Arbitragem Internacional. Disponível em: < https://ww2.stj.jus.br/publicacaoinstitucional/index.php/informativo/article/download/434/ 392>. Acesso em: 16 jan. 2021.

CÂMARA DE COMÉRCIO INTERNACIONAL (ICC). Regulamento de Arbitragem. Regulamento de Mediação, 2 mar; 2017. Disponível em: $<$ https://iccwbo.org/content/uploads/sites/3/2017/02/ICC-2017-Arbitration-and-2014Mediation-Rules-portuguese-version.pdf $>$. Acesso em: 2 jan. 2021.

CHRISTENSEN, John; COLEMAN, Pete; KAPOOR, Sony. Tax Avoidance, Tax Competition and Globalization: Making tax justice a focus for global activism. 28 out. 2004. Disponível em:<https://www.researchgate.net/profile/John_Christensen 8/publication/237424665_Tax_Avoidance_Tax_Competition_and_Globalisation_making_t ax_justice_a_focus_for_global_activismi/links/588f46f945851567c9405eac/TaxAvoidance-Tax-Competition-and-Globalisation-making-tax-justice-a-focus-for-globalactivismi.pdf >. Acesso em: 21 jan. 2021.

COOTER, Robert; UELEN, Thomas. Direito e Economia. São Paulo: Bookman, 2010.

ENGELMANN, Fabiano. O espaço da arbitragem no Brasil: notáveis e experts em busca de reconhecimento. Revista de Sociologia Política, Curitiba, v. 20, n. 44, nov. 2012. 
FONASTER, Mateus; SOARES, Fabrício. Globalização e os Meios Adequados de Solução de Conflitos: Da importância da arbitragem para empresas transnacionais. Revista Eletrônica de Direito Processual - REDP, Rio de Janeiro, ano 14. v. 21. n. 1, jan./abr. 2020.

HENRY, James. The Price of Offschore Revisited. Tax Justice Network, jul. 2012.

INTERNATIONAL CENTRE FOR DISPUTE RESOLUTION. Procedimentos para a Resolução de Disputas Internacionais, 1 jun. 2014. Disponível em: < https://www.icdr.org/sites/default/files/document_repository/International_Dispute_Resolu tion_Procedures_Portuguese_0.pdf >. Acesso em: 15 jan. 2021.

LOBO, Carlos Augusto. História e Perspectivas da Arbitragem no Brasil. Revista de Arbitragem e Mediação, São Paulo, v. 50, set. 2016. Disponível em: $<$ http://www.mpsp.mp.br/portal/page/portal/documentacao_e_divulgacao/doc_biblioteca/b ibli_servicos_produtos/bibli_boletim/bibli_bol_2006/RArbMed_n.50.06.PDF>. Acesso em: 16 jan. 2021.

MANGE, Flávia. Processo Arbitral: Aspectos transnacionais. São Paulo: Quartier Latin, 2014.

MANGE, Flávia et al. Lei Modelo da UNCITRAL sobre Arbitragem Comercial Internacional1985, com as alterações adotadas em 2006. Disponível em: < http://www.cbar.org.br/leis_intern_arquivos/Lei_Modelo_Uncitral_traduzida_e_revisada_ versao_final.pdf>. Acesso em: 16 jan. 2021.

MARINONI, Luiz Guilherme; AREHART, Sérgio Cruz; MITIDIERO, Daniel. Curso de Processo Civil. Tutela dos Direitos Mediante Procedimentos Diferenciados. $2^{\mathrm{a}}$ ed. São Paulo: Revista dos Tribunais, 2015.

MOREIRA JÚNIOR, Gilberto. Bitributação Internacional e Elemento de Conexão. São Paulo: Aduaneiras, 2003.

PINHEIRO, Luís de Lima. Direito aplicável ao mérito da causa na arbitragem transnacional. Revista da Ordem dos Advogados, Lisboa, ano 63, v. I e II, abr. 2003. Disponível em:< https://portal.oa.pt/publicacoes/revista/ano-2003/ano-63-vol-i-ii-abr2003/>. Acesso em: 16 jan. 2021.

REZEK, José Francisco. Direito Internacional Público: Curso elementar. 13 ed. São Paulo: Saraiva, 2011.

TEIXEIRA, Sálvio de Figueiredo. Conferência proferida no seminário "A arbitragem e o Brasil - uma perspectiva múltipla". São Paulo, 13 nov. 1996. Disponível em: <https://core.ac.uk/download/pdf/79062893.pdf>. Acesso em: 16 fev. 2021.

USA. Administrative Dispute Resolution Act of 1996. Sec. 572. General authority. Disponível em: <https://www.adr.gov/adrguide/adra1996.html\#572>. Acesso em: 4 fev. 2021. 
WEBER, Max. Conceitos Sociológicos. Tradução de Artur Morão. Covilhã: Lusofia, 2010 .

WORLD BANK GROUP. A Economia nos Tempos de Covid-19. Brasil. Disponível em: $<$ https://www.worldbank.org/pt/country/brazil/publication/latin-america-brazil-economycoronavirus-pandemic-covid-19>. Acesso em: 17 jan. 2021.

Recebido em: 10/10/2021

Aprovado em: 10/11/2021

Publicado em: 12/11/2021 